\title{
REVIEW
}

\section{Chronic lung disease and the perception of breathlessness: a clinical perspective}

\author{
J.G.W. Burdon*, M.C.F Pain**, A.R. Rubinfeld**, A. Nana
}

\begin{abstract}
Chronic lung disease and the perception of breathlessness: a clinical perspective. J.G.W. Burdon, M.C.F. Pain, A.R. Rubinfeld, A. Nana. CERS Journals Ltd 1994.

ABSTRACT: Breathlessness is an extremely common symptom. Its genesis is incompletely understood but is known to be largely determined by many of the mechanical factors associated with the act of breathing. As with all subjective sensations various other factors including volition, behavioural style and other cortical and subcortical factors play a part in its genesis.

The relief of breathlessness is primarily directed at the underlying disorder. In those conditions and situations where specific therapy has little to offer or little impact it is reasonable to consider ways of reducing the perception of breathlessness by pharmacological means. However, to date there is no convincing evidence that use of drugs in the pursuit of the relief of breathlessness has any specific effect in modifying the perception of this often distressing symptom. Any reduction in breathlessness achieved in this way can be adequately explained in terms of a reduction in ventilation and other indices of respiratory mechanics.
\end{abstract}

Eur Respir J., 1994, 7, 1342-1349.

Breathlessness is the commonest reason for medical consultation in patients with lung disease, and yet it remains difficult to define and its pathogenesis is not fully understood. It is even difficult for some patients to describe the sensations which comprise breathlessness, although it is a symptom which is experienced normally during everyday activities.

A definition which has been proposed suggests that breathlessness arises when there is a recognition by the subject of an inappropriate relationship between respiratory work and total body work [1]. This definition reinforces the subjective nature of breathlessness but says nothing about its mechanism, and infers that past experience is drawn upon to decide on the appropriateness or otherwise of the work relationships. Past experience would allow recognition of "normal" breathlessness associated with a range of physical activities (it's normal to feel a certain degree of breathlessness after a $100 \mathrm{~m}$ sprint) and also "abnormal" breathlessness (it's not normal to feel the same amount of breathlessness following a gentle walk). Clearly, factors other than those mechanical are involved in the generation of breathlessness. These include behavioural style, volition and other cortical and subcortical elements. These aspects are also addressed in this review.

Since respiratory work is an important determinant of breathlessness and can be objectively assessed, it is tempting to assume that a complete analysis of breathlessness can be achieved by its measurement. Respiratory work,
*Dept of Respiratory Medicine, St Vincent's Hospital, Fitzroy, Australia. **Dept of Thoracic Medicine, Royal Melbourne Hospital, Parkville, Australia. †Dept of Medicine, Siriraj Hospital, Bangkok, Thailand.

Correspondence: J.G.W. Burdon Dept of Respiratory Medicine, St Vincent's Hospital, 41 Victoria Parade, Fitzroy, Victoria, Australia 3065.

Keywords:Breathlessness, chronic lung disease.

Received: April 191993

Accepted after revision March 11994

Psychophysics of breathlessness studies (MCFP, ARR, JGWB) have been supported by grants-in-aid from the NH \& MRC of Australia and an Overseas Travelling Fellowship (JGWB). Whilst in Melbourne, AN held a Travelling Fellowship from Mahidol University, Thailand. which is mainly ventilatory work, results when a certain ventilatory drive works against a ventilatory load. The components of ventilatory load are elastic (stretching load) and resistive (airflow), one or both of which are increased in many respiratory diseases. Increases in elastic load are a feature of the various conditions associated with diffuse interstitial lung disease. Asthma, obstructive bronchitis and emphysema are common examples of conditions associated with increased resistive ventilatory load. The relationship between the drive and load to breathing is balanced to achieve adequate ventilation. An increase in load will normally result in an increase in drive to maintain ventilation and gas exchange. Drive increases may also occur in the presence of a normal ventilatory load, in circumstances where there is a demand for higher ventilation due to exercise or oxygen deficient environments. Thus, ventilation can be maintained over a wide range of demands. Increases in respiratory work can be considered as being due to increased ventilatory load, increased ventilatory drive, or a combination of both factors. In all instances, breathlessness could be anticipated.

\section{Quantification of breathlessness}

Although the presence or absence of breathlessness might be inferred from a physical examination or the measurement of lung function, it remains a symptom and, 
as such, its quantification requires an opinion from the individual, which will be based on the perception of the load and drive and modified by past experience. Attempts to introduce some objectivity have resulted in various scoring techniques in which a subject is asked to quantify breathlessness. Various scales have been developed. Thus, breathlessness may be graded (I-IV) according to the amount of exertion required to induce it [2], or by the use of linear analogue self-assessment or Borg scales [3-5].

Breathlessness may be generated by the underlying lung condition and its fluctuations. The latter may be spontaneous or, in the case of asthma, induced artificially. In these instances, it is intrinsic load that is being assessed and the situation would seem to be more realistic than imposing various impedances to breathing using external circuits. Whilst there is some evidence that spontaneous and laboratory-induced asthmatic episodes are similar [6], it is still not clear that studies with extrinsic load variations are completely applicable to the breathless patient. This is because the use of external loading circuits requires the subject to assess the magnitude or size of the added resistance or elastance and, in doing so, generate an index of respiratory sensation. The latter does not necessarily equate with the symptom of breathlessness but does provide useful information which may be extrapolated to the clinical arena.

In this way, with an index of respiratory sensation and accurate knowledge of the applied load provided by these studies, the relationship between sensation and stimulus (load) has been explored in normal subjects and patients with lung disease and found to follow a power function, as suggested by STEVENS [7] for other sensory modalities.

\section{Lung disease}

There are two aspects of breathlessness perception of direct clinical relevance. Firstly, do patients exhibit impairment of perception of background loads (i.e. impairment of detection and magnitude estimation); in other words, are they less breathless than might be expected for the degree of severity of their lung disease? Secondly, do they have impaired ability to detect acute changes in mechanical load (discrimination impairment), such as acute increases in airflow obstruction?

\section{Impairment of perception and temporal adaptation}

In experiments in which both of these aspects were combined, patients with asthma were asked to confirm that they were initially symptom free, and to assess their status following the induction of asthma using methacholine aerosol [8]. Spirometric data showed that $15 \%$ of subjects were unable to sense the presence of marked airway obstruction present either initially or following an episode of induced (methacholine) airflow obstruction. This study confirmed a well-recognized clinical impression that some patients tolerate severe respiratory loads with little or no complaint of breathlessness. It was not possible, however, to determine if this tolerance was an inherent individual characteristic or an acquired property in the face of chronic load increase, i.e. temporal adaptation.

In a similar study [5] of asthmatic patients undergoing histamine provocation, it was found that those patients with a resting forced expiratory volume in one second $\left(\mathrm{FEV}_{1}\right)$ of less than $80 \%$ predicted experienced similar degrees of breathlessness to those patients with normal resting $\mathrm{FEV}_{1}$, but for all degrees of breathlessness were significantly more obstructed. This downgrading of the sensory experience is consistent with the phenomenon of temporal adaptation. It is not known what factors might lead to this readjustment, nor how rapidly it can occur. Logic would suggest that such a downgrading would take some significant length of time. However, it is apparent that some changes occur quite quickly, as at least some reduction in respiratory sensation has been shown to take place within a few minutes $[9,10]$. In fact, in the latter study [10], the authors indicated that the diminution of respiratory sensation in the presence of a persistent background load probably follows an exponential decay. Whether the perceptive threshold can be readjusted back towards normal (recovery function) by inducing chronic improvement in respiratory load, and if so how quickly it occurs, is an important but as yet unanswered question.

\section{Threshold of perception}

The concept of a perceptive threshold has been explored by trying to determine by how much lung function had to deteriorate before subjects first noticed breathlessness, and by noting whether the ratio of change in lung function to threshold varied with a changing initial value [11, 12]. Using lung volume (i.e. the degree of hyperinflation) and airway resistance changes as markers of lung dysfunction in acute asthma, it was demonstrated that a change of about $25 \%$ was necessary before any change in symptoms was noticed [11]. This would suggest that the Weber fraction (i.e. the percentage increase in load required to produce a just noticeable difference in sensation) was of the order of 0.25 . This value is similar to the results of BURKI and co-workers [13], who found a mean Weber fraction of 0.36 for asthmatic patients, which increased to 0.48 after aerosol bronchodilator (difference not significant). BURKI [14] later showed similar results in patients with restrictive lung disease, with Weber fractions both for resistive and elastic loads of 0.25 and 0.21 , respectively.

In all these studies, although considerable variation between individuals was observed, there was no significant difference in the Weber fraction between the patients and the normal controls. These studies suggest that both normal subjects and patients with lung disease perceive changes in their respiratory status in the same way. However, in keeping with Weber's Law, in patients with abnormal mechanics larger changes in background load are required before changes in sensation occur. 


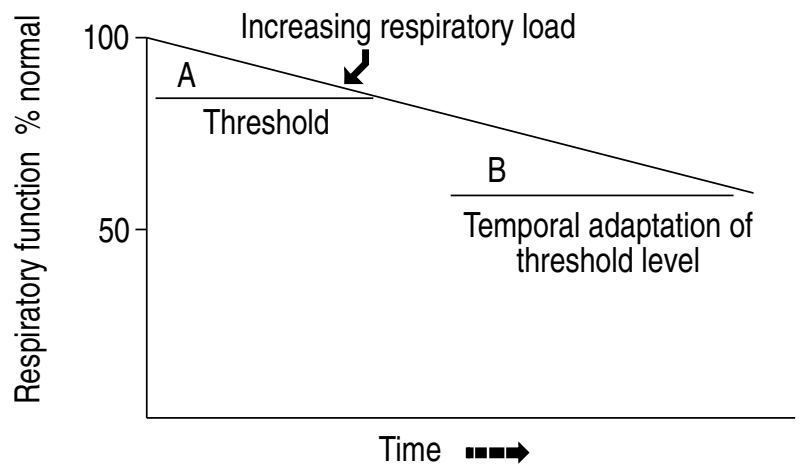

Fig. 1. - Theoretical changes in threshold of perception with increasing respiratory mechanical impairment. A: initial threshold; B: readjusted threshold.

Interestingly, STUBBing et al. [15] have shown in normal subjects that the Weber fraction is constant over a wide range of background resistances but rises when the background resistance is low. This result might explain the increase in Weber fraction to 0.48 in asthmatic patients after the administration of bronchodilator in the earlier report of BURKI and co-workers [13]. RUBINFELD and PAIN [11], in their studies, also noted that greater initial chronic background load abnormalities required larger changes in pulmonary mechanics before detection occurred as expected from Weber's Law. However, if the change in background load was recent, such as that induced by methacholine, then a smaller percentage change to threshold was needed.

Whilst not completely explained by Weber's Law, such as had been suggested from studies in normal subjects [16], the results of their studies would be consistent with the concept of a threshold of perception which behaved as in figure 1. This figure shows that, in the presence of deteriorating baseline lung function the below threshold area (A) becomes smaller (i.e. less change from baseline to produce symptoms) but with continuing deterioration in baseline value, the threshold becomes "readjusted", so that in the new situation (B) significant disability can be tolerated without symptoms.

\section{Assessment of magnitude of respiratory loading}

The question of assessment of the extent of deterioration (magnitude assessment) of respiratory sensation can only be conveniently studied by using external loading experiments of the type introduced by CAMPBELL and coworkers $[17,18]$, in the early 1960 s, and subsequently used extensively by other workers. Combining open magnitude scaling techniques with resistive or elastic load circuitry, the relationship between load and sensory score (respiratory sensation) has been examined both in normal subjects and in patients with a variety of respiratory disorders.

KILLIAN and co-workers [19] have used these methods in studies designed to determine the important factors associated with the genesis of respiratory sensation. They found that the perceived magnitude of resistive loads was directly related to the peak airway pressure during inspiration, and only indirectly to the actual resistance added.
Similar studies with elastic loads [19] indicated that the respiratory sensation experienced was also directly related to the peak airway pressure during inspiration, and only indirectly to the actual elastic load itself.

In subsequent experiments, these and other workers showed that breathing frequency and inspiratory duration [20], the presence or absence of respiratory muscle weakness [21] or fatigue [22] ventilatory drive [23] and length tension relationships [24] were also variables which affect respiratory sensation. The findings of these experiments are significant because they indicate that respiratory sensation and thus by extrapolation breathlessness is determined by many factors associated with the act of breathing. Other less tangible and much less easily measured factors have also been implicated in the genesis of respiratory sensation.

Clinicians have for many years recognized that breathlessness is a highly variable symptom. It is often distressing, but at other times seemingly of little concern to the patient, despite similar degrees of pulmonary disease or mechanical impairment of the respiratory apparatus. This disparity underscores the argument that mechanical factors alone do not provide a complete explanation for the genesis of breathlessness. Furthermore, increases in minute ventilation alone can be interpreted quite differently from a perceptive point of view by different subjects.

Experiments under conditions of respiratory muscle weakness or fatigue have indicated that breathlessness is not merely the perception of ventilatory drive or other mechanical aspects of ventilation. In their well-known experiments in the late 1960s, CAMPBELL and co-workers $[25,26]$ found that prolonged breathholding under conditions of total muscular paralysis did not result in any respiratory distress. These findings were at variance with earlier experimental findings of distress and smothering feelings in a normal volunteer [27], and paralysed ventilated patients [28]. KILLIAN and co-workers [29] have shown that both breathlessness and the sense of effort generated by the respiratory muscles increases not only as the mechanical load increases but also as the lung volume at which it is measured increases. They concluded that "breathlessness and effort are identical and mediated by the same mechanism".

Further work in which the relationship between breathlessness and respiratory effort has been examined has suggested that the sense of effort at any given ventilation is less when the stimulus for ventilation is mediated via reflex brainstem activity, compared with voluntary signals to the respiratory muscles [30]. The authors concluded that breathlessness and effort were not the same, and that effort was likely to be one of many factors that contributes to the sensation of breathlessness. These conclusions have been supported by the results of other experiments, where the sensation of dyspnoea was examined under conditions of complete muscular paralysis [31-33]. In these experiments, central chemoreceptor stimulation was found to lead to respiratory discomfort in the absence of any respiratory muscle contraction. Thus, it appears that under some conditions, such as muscle weakness or fatigue, the sense of effort may be the 
predominant factor, playing a lesser role under other conditions. At the cortical level, differences in behavioural style have also been shown to play a role in respiratory sensation [34-39] (see below). It is, therefore, of great importance that the knowledge of the variety of factors known to affect respiratory sensation be carefully considered and applied when these types of studies in the everyday setting are contemplated, or when clinical studies of breathlessness are being analysed.

Later work in respiratory sensation has applied these techniques and findings to the study of the way in which patients with respiratory disease assess the size of added loads to breathing. In 1981, GoTTFRIED and co-workers [40] employed magnitude estimation techniques and found that the perception of added resistive loads to breathing was impaired in patients with chronic airflow obstruction, whereas normal and asthmatic subjects were similar.

In subsequent studies, in which better control over the parameters of breathing and subject age was exercised, similar conclusions were reached in some [41, 42] but not in all $[43,44]$. In the latter studies, with more stringent control of confounding variables, no difference between normal subjects and patients with chronic airflow obstruction was found. WARD and STUBBING [44] also showed that there was no difference in sensory perception between patients with interstitial lung disease and normal subjects. Thus, these studies failed to demonstrate that patients with chronic lung disease have any impairment of sensory load perception once the threshold for perception had been achieved. However, in contrast to the previously reported detection and discrimination experiments, where just noticeable differences and Weber fractions were relatively constant, the slopes (exponents) of the relationship between the perceived magnitude of the added load and the physical stimulus itself were widely variable. The reason for this is not apparent, but may be due to differences in methodology and technique. Respiratory drive or other aspects of ventilatory control differences may also be responsible, since the study populations may not have been as homogeneous as the investigators would have wished.

It has also been shown [45] that those patients with airflow limitation whose sensory exponent for added resistive loads fell within the normal range demonstrated a good correlation between respiratory drive and their background mechanical load, whereas those patients with sensory exponents falling outside the confidence limits did not. The results of this study were interpreted as showing that respiratory drive adjustments to ventilatory loads are, at least in part, dependent on correct sensory perception. All these studies have provided much useful information about the genesis of respiratory sensation and the way in which both normal subjects and patients with chronic lung disease perceive the sensation of breathlessness.

Recently, the concept of sensory nerve ending stimulation within the airways independent of mechanical mechanisms as the stimulus responsible for the sensation of breathlessness has been reconsidered and discussed [46]. However, as a sole explanation for the sensation of breathlessness, this is considered very unlikely, particularly as previous workers have shown that upper and lower airway anaesthesia had no effect on the ability of normal subjects to detect added inspiratory resistive and elastic loads [47, 48].

\section{Clinical implications}

Many important decisions relating to management depend on the awareness by the patient with lung disease of his current respiratory status. An asymptomatic patient is unlikely to seek medical attention. Failure to appreciate a deteriorating situation will result in undertreatment of what may become a crisis, and patient compliance with regular medication is difficult if symptoms are absent.

It is, therefore, important to attempt to assess the perception of breathlessness in patients with chronic lung disease as part of the therapeutic strategy. In this regard, it has to be determined whether psychophysical techniques offer any advantage over the traditional grading scales for breathlessness. MAHLER and co-workers [49] have argued that scales such as the MRC scale, oxygen cost diagram and dyspnoea indices are more appropriate for assessing the disruption of lifestyle than studies using the exponent of Steven's power function. They found a good relationship between clinical dyspnoea ratings and simple pulmonary function abnormalities, but no correlation between psychophysical testing and functional impairment both in patients with chronic airflow obstruction [49] and interstitial lung disease [50].

In contrast, O'DonNELL and WEBB [51] examined the relationship between simple dyspnoea indices and lung function impairment in 37 patients with stable severe airflow obstruction. They found no differences in indices of airflow between groups with severe and moderate breathlessness, but noted that gas transfer was more impaired in the more severely breathless group and that ventilatory responses to exercise were excessive. These results reinforce the importance of ventilatory work in the genesis of breathlessness.

These findings are not really surprising. Dyspnoea indices and gradings are an attempt to put a numerical value on the degree of breathlessness by relating this to the reduction in physical activity, whereas psychophysical data are related more to the sensory experience and sensitivity to load changes. The latter tests have little to offer in the overall clinical assessment, except in the recognition of that subgroup of patients who have impaired perception.

Since formal psychophysical assessment is tedious, it is fortunate that impaired perception can be recognized by simple clinical means. The dysjunction between a simple objective test and a subjective score, particularly if observed on several occasions, is the hallmark of impaired perception, and will readily distinguish between patients who can accurately follow changes in their condition and those that cannot. Figure 2 shows the results of such a study in two patients with asthma. There is a good correlation between symptoms of breathlessness 


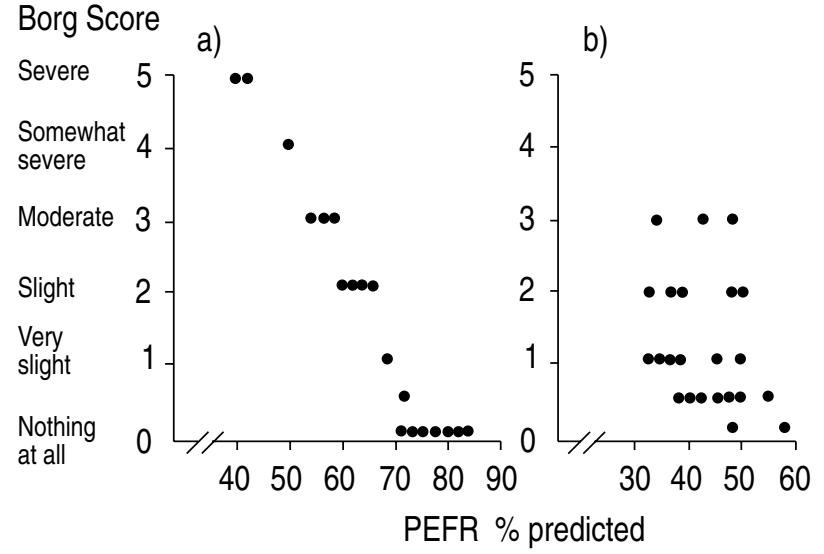

Fig. 2. - Correlation between symptoms of breathlessness and airflow obstruction in two patients. a) Results from a patient who can accurately recognize changes in airway calibre. b) Results from a patient who cannot accurately recognize changes in airway calibre. PEFR: peak expiratory flow rate.

and airflow obstruction in one subject (a) but not in the other (b). The latter patient, once identified, can be more aggressively treated and monitored.

\section{The use of drugs to alter the perception of breathlessness}

The improvement in knowledge concerning the genesis of and the perception of breathlessness has had little impact on therapy. Treatment of breathlessness is most effective when the primary cause can be identified and modified, but in those conditions in which treatment currently has little to offer, it is logical to explore the feasibility of modifying the perception of breathlessness in order to relieve distress. Many drugs, such as hydrocodeine [52-55], morphine [56-59], diazepam [60-63] and promethazine $[62,63]$, have been tested for their ability to relieve intractable breathlessness, with inconclusive results. Relief when obtained can, in most cases, be adequately explained by a reduction in respiratory work without the need to postulate any alteration in the perceptive mechanism or ability.

Opiates have long been popular therapy for the alleviation of breathlessness in patients with respiratory disease. They have, however, not achieved widespread usage, largely because of their potential side-effects, such as respiratory depression and addiction. Morphine has been used to reduce distressful symptoms, including breathlessness, in palliative care but its use in the longterm management of patients with chronic lung disease is more controversial. In a recent study, Young et al. [56] examined the effect of low dose inhaled morphine on exercise endurance in patients with chronic lung disease, and found that morphine increased exercise endurance. As this result could be misinterpreted as showing that inhaled morphine relieves breathlessness even though breathlessness per se was not measured, the study was subsequently repeated by LEUNG et al. [57], who assessed breathlessness using a modified Borg scale in a similar group of patients. They found no difference in the breath- lessness experienced during exercise, nor in exercise endurance, between the morphine and placebo treated arms of the study. In both studies, similar doses of morphine were used being of the order of 1-2 mg of morphine inhaled.

It is possible that these negative findings were doserelated and that a more satisfactory result could be achieved by the use of larger doses. Using oral morphine $(0.8$ $\left.\mathrm{mg} \cdot \mathrm{kg}^{-1}\right)$ in patients with severe chronic airflow obstruction, Light et al. [58] have shown that exercise endurance was increased and breathlessness, assessed using a modified Borg scale, significantly decreased following oral morphine treatment. The reduction in breathlessness in this study was achieved at the expense of an increase in arterial carbon dioxide tension, a reduction in ventilatory drive $\left(\mathrm{P}_{0.1}\right)$, and was thought by the authors to be due to a combination of lowered ventilatory requirements for a given workload and also to altered perception. However, in a subsequent study [59], where arterial blood gases remained stable, breathlessness and exercise tolerance were unchanged following the administration of diamorphine. This result suggests that the reduction in breathlessness in the study by Light et al. [58] is likely to be solely due to changes in ventilatory drive and not specifically to a modification in the perceptive process.

Other opiates have also been studied. Dihydrocodeine, administered orally prior to exercise, has been shown to relieve dyspnoea by $20 \%$ [52] (assessed using a visual analogue scale) in patients with chronic airflow obstruction. Minute ventilation and oxygen consumption were reduced in this study, despite an increase in exercise capacity. Similar findings have also been reported following the long-term administration of dihydrocodeine $[53,54]$. Endogenous opiates may also play a part in the perception and/or modification of breathlessness, and this concept is supported in general terms by the observation that naloxone restored blunted ventilatory responses in patients with chronic airflow obstruction [64].

Other drugs, in particular the benzodiazepines, have been studied for their effect on the relief of breathlessness. Enthusiasm for the therapeutic use of diazepam was engendered by the initial report of Mitchell-HeGGS et al. [61], who reported a "striking" reduction in breathlessness (subjectively assessed) in four male patients with the "pink puffer syndrome" when treated with this drug. This finding has not been sustained in other studies [62, 63]. This syndrome (severe airflow obstruction, relatively preserved gas exchange and severe breathlessness) probably merges with those subjects considered to have disproportionate breathlessness by BURNS and HowELL [60]. In the latter group, when contrasted with subjects with appropriate breathlessness, there appeared to be increased stress, anxiety and hyperventilation. It is probable, therefore, that the action of diazepam in relieving breathlessness in a specific subgroup is related to its anxiolytic properties, although it also causes respiratory depression (decreased ventilatory drive) as shown by reductions in carbon dioxide sensitivity. Its use in the long-term management of intractable breathlessness in severe chronic lung disease is not recommended. Promethazine was also studied by Woodcock et al. [62] 
and found to reduce breathlessness without altering lung function, results which were not supported in a subsequent study [63]. Other anxiolytics and the prostanoid indomethacin have been studied with variable results (chlorpromazine [66], alprazolam [67], and indomethacin $[68,69])$.

The modification of the perception of breathlessness by pharmacological means in the pursuit of relieving symptoms has received much attention. At the present time, the results of these studies have not yielded any specific answers, or provided any clear direction with respect to the specific suppression of breathlessness at a central level. Those studies which conclude that breathlessness can be reduced by pharmacological means need to be considered with great care, because in almost all cases the reduction in breathlessness can be explained in terms of decreased respiratory work secondary to a reduction in ventilatory drive and/or other aspects of the mechanical or chemical control of breathing. Furthermore, a marked placebo effect has been demonstrated in some patients with airflow obstruction [70]. These findings, in addition to the significant incidence of potentially serious side-effects, imply that the routine prescription of drugs in pursuit of the relief of breathlessness cannot, at present, be recommended.

\section{Psychological interventions in the modification of breath- lessness}

Psychological factors may modify symptoms [62]. Previous experience has been shown to modify breathlessness in normal subjects $[36,37]$ and breathlessness may be increased by anxiety or depression [35]. In some situations, these symptoms can be improved by simple explanation of the underlying respiratory problem or disease process. Behavioural style has been reported to affect the way in which an individual recognizes added resistive loads [36, 39], and for this reason it is possible that in some situations psychological techniques, such as relaxation therapy, behaviour modification, meditation and hypnosis, may be helpful.

\section{Conclusions}

Breathlessness is a symptom which primarily requires analysis as a marker of increased ventilatory load or drive. Its perception is commonly impaired in patients with respiratory disease, but it is not clear whether this impairment is purely an expression of temporal adaptation or whether other aspects of the sensory process, such as the pattern of breathing, or the variation of detection found among normal subjects, carry over and play a part. Furthermore it is important to realize that nonmechanical factors, such as the sense of respiratory effort, volitional input and the behavioural style, are all implicated in the genesis of this common symptom.

Studies using psychophysical techniques may allow a better understanding of the nature of breathlessness as a sensation and expand the interrelationship between fac- tors producing and modifying it. Clinical scales are more useful in the assessment of breathlessness for practical everyday purposes and are easy and simple to apply.

The treatment of breathlessness is primarily aimed at the underlying disorder. In those conditions and situations where specific therapy is not possible or has little to offer, it is reasonable to consider ways of reducing the perception of breathlessness by pharmacological means. There is no convincing evidence that any of the drugs used in this endeavour have any specific effect in modifying the perception of breathlessness. Any reduction of breathlessness achieved can be quite adequately explained in terms of a reduction in ventilation and respiratory work.

\section{References}

1. Howell JBL. Breathlessness in pulmonary disease. In: Howell JBL, Campbell EJM, eds Breathlessness. Oxford, Blackwell, 1966; pp. 165-177.

2. Fletcher CM. The clinical diagnosis of pulmonary emphysema: an experimental study. Proc Roy Soc Med 1952; 45: 577-584.

3. Priestman TJ, Baum M. Linear analysis self-assessment. Lancet 1976; i: 899-900.

4. Borg GAV. Psychophysical basis of perceived exertion. Med Sci Sports Exerc 1982; 14: 377-381.

5. Burdon JGW, Juniper EF, Killian KJ, Hargreave FE, Campbell EJM. The perception of breathlessness in asthma. Am Rev Respir Dis 1982; 126: 825-828.

6. Rubinfeld AR, Pain MCF. Bronchial provocation in the study of sensations associated with disordered breathing. Clin Sci Mol Med 1977; 52: 423-428.

7. Stevens SS. On the psychophysical law. Psychol Rev 1957; 64: 153-181.

8. Rubinfeld AR, Pain MCF. Perception of asthma. Lancet 1976; i: 882-884.

9. McCloskey DI. The effects of pre-existing loads upon detection of externally applied resistances to breathing in man. Clin Sci Mol Med 1973; 45: 561-564.

10. Burdon JGW, Killian KJ, Stubbing DG, Campbell EJM. Effect of background loads on the perception of added loads to breathing. J Appl Physiol: Respirat Environ Exercise Physiol 1983; 54: 1222-1228.

11. Rubinfeld AR, Pain MCF. Conscious perception of bronchospasm as a protective phenomenon in asthma. Chest 1977; 72: 154-158.

12. Rubinfeld AR, Pain MCF. How mild is mild asthma? Thorax 1977; 32: 177-181.

13. Burki NK, Mitchell K, Chaudhary BA, Zechman FW. The ability of asthmatics to detect added resistive loads. Am Rev Respir Dis 1978; 117: 71-75.

14. Burki NK. Detection of added respiratory loads in patients with restrictive lung disease. Am Rev Respir Dis 1985; 132: $1210-1213$.

15. Stubbing DG, Killian KJ, Campbell EJM. Weber's law and resistive load detection. Am Rev Respir Dis 1983; 127: 5-7.

16. Wiley RL, Zechman FW. Perception of added resistance in humans. Respir Physiol 1966/67; 2: 73-87.

17. Campbell EJM, Freedman S, Smith PS, Taylor ME. The ability of man to detect added elastic loads to breathing. Clin Sci 1961; 20: 223-231.

18. Bennett ED, Jayson MIV, Rubenstein D, Campbell EJM. 
The ability of man to detect added nonelastic loads to breathing. Clin Sci 1962; 23: 155-162.

19. Killian KJ, Bucens DD, Campbell EJM. Effect of breathing patterns on the perceived magnitude of added loads to breathing. J Appl Physiol: Respirat Environ Exercise Physiol 1982; 52: 578-584.

20. Killian KJ, Summers E, Basalygo M, Campbell EJM. Effect of frequency on perceived magnitude of added loads to breathing. J Appl Physiol 1985; 58: 16161621.

21. Campbell EJM, Gandevia SC, Killian KJ, Mahutte CK, Rigg JRA. Changes in the perception of inspiratory resistive loads during partial curarization. J Physiol (Lond) 1980; 309: 93-100.

22. Ward ME, Stubbing DG. Effect of respiratory muscle fatigue on the perception of added inspiratory loads. Am Rev Respir Dis 1984; 129: 652-656.

23. Burdon JGW, Killian KJ, Campbell EJM. Effect of ventilatory drive on the perceived magnitude of added loads to breathing. J Appl Physiol: Respirat Environ Exercise Physiol 1982; 53: 901-907.

24. Campbell EJM, Howell JBL. The sensation of dyspnoea. Br Med Bull 1963; 17: 36-40.

25. Campbell EJM, Freedman S, Clark TJH, Robson JG, Norman J. The effect of muscular paralysis on the duration and sensation of breathholding. Clin Sci 1967; 32: 425-432.

26. Campbell EJM, Godfrey S, Clark TJH, Freedman S, Norman J. The effect of muscular paralysis on the duration and sensation of breathholding during hypercapnia. Clin Sci 1969; 36: 323-328.

27. Smith SM, Brown HO, Toman JEP, Goodman LS. The lack of cerebral effects of d-tubocurarine. Anaesthesia 1947; 18: 1-14.

28. Opie LH, Smith AC, Spalding JMK. Conscious appreciation of the effects produced by independent changes of ventilation volume and end-tidal $\mathrm{CO}_{2}$ in paralysed patients. J Physiol (Lond) 1959; 149: 494-499.

29. Killian KJ, Gandevia SC, Summers E, Campbell EJM. Effect of increased lung volume on perception of breathlessness, effort and tension. J Appl Physiol: Respirat Environ Exercise Physiol 1984; 57: 686-691.

30. Demediuk BH, Manning H, Lilly J, et al. Dissociation between dyspnoea and respiratory effort. Am Rev Respir Dis 1992; 146: 1222-1225.

31. Banzett RB, Lansing RW, Reid MB, Adams L, Brown R. "Air hunger" arising from increased $\mathrm{PCO}_{2}$ in mechanically-ventilated quadriplegics. Respir Physiol 1989; 76: 5368.

32. Banzett RB, Lansing RW, Brown R, et al. "Air hunger" arising from increased $\mathrm{PCO}_{2}$ persists after complete neuromuscular block in humans. Respir Physiol 1990; 81: $1-18$.

33. Gandevia SC, Killian KJ, McKenzie DK, et al. Dyspnea during complete paralysis in human subjects. Am Rev Respir Dis 1993; 147 (Suppl.): A171.

34. Hudgel DW, Cooperson DM, Kinsman RA. Recognition of added resistive loads in asthma. Am Rev Respir Dis 1982; 126: 121-125.

35. Dales RE, Spitzer WO, Schechter MT, Suissa S. The influence of psychological status on respiratory symptom reporting. Am Rev Respir Dis 1989; 139: 14591463.

36. Wilson RC, Jones PW. Influence of prior ventilatory experience on the estimation of breathlessness during exercise. Clin Sci 1990; 78: 149-153

37. Wilson RC, Oldfield WLG, Jones PW. Effect of resi- dence at altitude on the perception of breathlessness on return to sea level in normal subjects. Clin Sci 1993; 84: $159-167$

38. Hudgel DW, Kinsman KA. Interactions among behavioural style, ventilatory drive and load recognition. Am Rev Respir Dis 1983; 128: 246-248.

39. Tiller J, Pain M, Biddle N. Anxiety disorder and perception of inspiratory resistive loads. Chest 1987; 91: 547-551.

40. Gottfried SB, Altose MD, Kelsen SG, Cherniack NS. Perception of changes in airflow resistance in obstructive pulmonary disorders. Am Rev Respir Dis 1981; 124: 566-570.

41. Gottfried SB, Redline S, Altose MD. Respiratory sensation in chronic pulmonary disease. Am Rev Respir Dis 1985; 132: 954-959.

42. Burki NK. Effects of bronchodilation on magnitude estimation of added resistive loads in asthmatic subjects. Am Rev Respir Dis 1985; 129: 225-229.

43. Nana A, Burdon JGW, Pain MCF. Perceived magnitude of added resistive loads in patients with chronic respiratory disease. Aust NZ J Med 1985; 15: 500.

44. Ward ME, Stubbing DG. Effect of chronic lung disease on the perception of added inspiratory loads. Am Rev Respir Dis 1985; 132: 652-656.

45. Pain MCF, Nana A, Burdon JGW. Sensory perception and load-drive relationship in patients with airflow obstruction. Aust NZ J Med 1989; 19: 661.

46. Barnes PJ. Poorly perceived asthma. Thorax 1992; 47: 408-409.

47. Chaudhary BA, Burki NK. Effects of airway anaesthesia on the ability to detect added inspiratory resistive loads. Clin Sci Mol Med 1978; 54: 621-626.

48. Chaudhary BA, Burki NK. The effects of airway anaesthesia on detection of added inspiratory elastic loads. Am Rev Respir Dis 1980; 122: 635-639.

49. Mahler DA, Rosiello RA, Harver A, Lentine T, McGovern JF, Daubenspeck JA. Comparison of clinical dyspnoea ratings and psychophysical measurements of respiratory sensation in obstructive airway disease. Am Rev Respir Dis 1987; 135: 1229-1233.

50. Mahler DA, Harver A, Rosiello R, Daubenspeck JA. Measurement of respiratory sensation in interstitial lung disease. Evaluation of clinical dyspnoea ratings and magnitude scaling. Chest 1989; 96: 767-771.

51. O'Donnell DE, Webb KA. Breathlessness in patients with severe chronic airflow obstruction. Chest 1992; 102: 824-831.

52. Woodcock AA, Gross ER, Gellert A, Shah S, Johnson M, Geddes DM. Effects of dihydrocodeine, alcohol and caffeine on breathlessness and exercise tolerance in patients with chronic obstructive lung disease and normal blood gases. N Engl J Med 1981; 305: 16111616.

53. Woodcock AA, Johnson MA, Geddes DM. Breathlessness, alcohol and opiates. N Engl J Med 1982; 306: 1363-1364.

54. Johnson MA, Woodcock AA, Geddes DM. Dihydrocodeine for breathlessness in "pink puffers". Br Med $J$ 1983; 286: 675-677.

55. Stark RD, Morton PB, Sharman P, Percival PG, Lewis JA. Effects of codeine on the respiratory responses to exercise in healthy subjects. Br J Clin Pharmacol 1983; 15: 355-359.

56. Young IH, Daviskas E, Keena VA. Effect of low dose nebulised morphine on exercise endurance in patients with chronic lung disease. Thorax 1989; 44: 387-390. 
57. Leung R, Hill P, Burdon. The effect of inhaled morphine on the development of breathlessness during exercise in patients with chronic lung disease. Submitted for publication, 1993.

58. Light RW, Muro JR, Sato RI, Stansbury DW, Fischer CE, Brown SE. Effects of oral morphine on breathlessness and exercise tolerance in patients with chronic obstructive pulmonary disease. Am Rev Respir Dis 1989; 126: $126-133$.

59. Eiser N, Denman WT, West C, Luce P. Oral morphine: lack of effect on dyspnoea and exercise tolerance in the "pink puffer" syndrome. Eur Respir J 1991; 4: 926-931.

60. Rice KL. Treatment of dyspnoea with psychotropic agents (Editorial). Chest 1986; 90: 789.

61. Mitchell-Heggs P, Murphy K, Minty K, et al. Diazepam in the treatment of dyspnoea in the "Pink Puffer" Syndrome. $Q J$ Med 1980; 49: 9-20.

62. Woodcock AA, Gross ER, Geddes DM. Drug treatment of breathlessness: contrasting effects of diazepam and promethazine in pink puffers. $B r$ Med $J$ 1981; 283: 343-346.

63. Stark RD, Gambles SA, Lewis JA. Methods to assess breathlessness in healthy subjects: a critical evaluation and application to analyse the acute effects of diazepam and promethazine on breathlessness induced by exercise or by exposure to raised levels of carbon dioxide. Clin Sci 1981; 61; 429-439.

64. Santiago TV, Remolina C, Scoles V, Edelman NH. Endorphins and the control of breathing. $N$ Engl J Med 1981; 304: 1190-1195.

65. Burns BH, Howell JBL. Disproportionately severe breathlessness in chronic bronchitis. Q J Med 1969; 38: 277-294.

66. O'Neill PA, Morton PB, Stark RD. Chlorpromazine: a specific effect on breathlessness? Br J Clin Pharmacol 1985; 19: 793-797.

67. Man GCW, Hsu K, Sproule BJ. Effect of alprazolam on exercise and dyspnoea in patients with chronic obstructive pulmonary disease. Chest 1986; 90: 832-836.

68. O'Neill PA, Stark RD, Morton PB. Do prostaglandins have a role in breathlessness? Am Rev Respir Dis 1985; 132: 22-24.

69. Schiffman GL, Stansbury DW, Fischer CE, Sato RI, Light $\mathrm{RW}$, Brown SE. Indomethacin and perception of dyspnoea in chronic airflow obstruction. Am Rev Respir Dis 1988; 137: 1094-1098.

70. Noseda A, Schmerber J, Prigogine T, Yernault JC. Perceived effect on shortness of breath of an acute inhalation of saline or terbutaline: variability and sensitivity of an analogue scale in patients with asthma or COPD. Eur Respir J 1992; 5: 1043-1053. 